\title{
NOTES
}

\section{SPHEROPLAST-LIKE STRUC'TURES IN ESCHERICHIA COLI DEMONSTRATED BY SCANNING ELECTRON MICROSCOPY}

\author{
Takeshy Nishino and Shozo Nakazawa \\ Department of Microbiology, \\ Kyoto College of Pharmacy, \\ Kyoto, Japan
}

(Received for publication July 4, 1972)

Although available commercially since 1965 , the scanning electron microscope has been little used by microbiologists. However, several studies have recently been reported on the scanning electron microscopy of antibiotic-induced alterations in the surface morphology of bacterial cells ${ }^{1,2,3,4}$. In our previous paper $^{5)}$ we presented the results of the morphological investigation by electron microscopy on Staphylococcus aureus and Escherichia coli exposed to cephalexin. It is the purpose of this paper to report studies in which the scanning electron microscope was utilized to observe the effects of cephalexin on the surface morphology of $E$. coli NIH.

Heart infusion broth (Nissan) was inoculated with $E$. coli NIH and incubated at $37^{\circ} \mathrm{C}$. Cephalexin was added to cultures at the 5 th hour of logarithmic phase of growth. Organisms were harvested by centrifugation at 3,000 r.p.m. for 5 minutes, washed three times in KeLLENBERGER buffer solution, fixed for 16 hours in $1 \%$ solution of osmium tetroxide according to the method of Kerrenberger et al. ${ }^{6}$, and dehydrated with alcohol series. A drop of each suspension was air-dried on $5 \mathrm{~mm}$ microscope coverslips. The cover-slips were coated with carbon and pure gold in a high-vacuum unit (JEOL JEE 4B) to obtain a uniform coating approximately $100 \AA$ thick. A JEOL JSMU3 scanning electron microscope operating at accelerating voltage of $9 \mathrm{kV}$ was used.

Untreated E. coli NIH cells appeared to have smooth contours (Fig. 1).

The effects of cephalexin on the surface morphology of E. coli NIH are shown in Figs. 2, 3 and 4 . The degree of morphological changes was found to be dependent on the concentration of cephalexin added. Exposure to 32 minimal inhibitory concentration (MIC) of cephalexin resulted in the formation of marked filamentous cells and spherical cells having multiple small saccular outpouchings, probably representing spheroplasts (Figs. 2 and 3). It appeared that the spherical cell became more and more enlarged and eventually ruptured (Fig. 4). It is noteworthy that the spherical cell had multiple small saccular outpouchings.

Greenwood and O'Grady' studied the effect of aminobenzylpenicillin on the surface structures of Staphylococcus aureus and Streptococcus pyogenes. In addition, KLAiner and PERKINS ${ }^{2)}$ reported on the effects of penicillin $G$ and cephalothin on the surface morphology of $S$. aureus and $E$. coli, respectively. But they did not observe such spheroplast-like structure as we indicate in this paper.

\section{Acknowledgement}

The authors are greately indebted to Takeda Chemical Industries, Ltd. (Osaka) for making scanning electron microscope available for this study.

\section{References}

1) Greenwood, D. \& F. O'Grady: Antibioticinduced surface changes in microorganisms demonstrated by scanning electron microscopy. Science $163: 1076 \sim 1077,1969$

2) KlaINer, A. S. \& R. L. Perkins: Antibioticinduced alterations in the surface morphology of bacterial cells: A scanning-beam electron microscope study. J. Infect. Dis. $122: 323 \sim 328,1970$

3) Klitiner, A.S. \& R. L. Perkins: Normal and abnormal morphology of microorganisms. A scanning-beam electron microscope study. I. Amer. Med. Assoc. 215 : 1655 1657, 1971

4) Perkins, R. L. \& A. S. Kuainer : Carbenicillin-induced alterations in the surface morphology of bacteria: A scanning-beam electron microscope study. Antimicr. Agents \& Chemoth. $-1970: 100 \sim 104,1971$ 
Fig. 1. Normal Escherichia coli NIH cells. $(\times 8,000)$

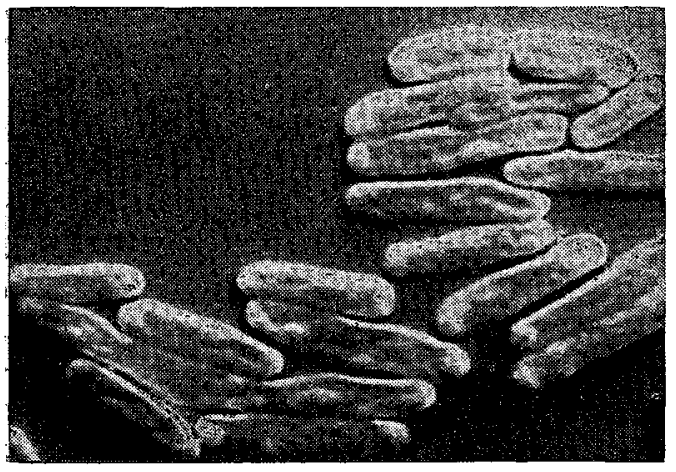

Fig. 2. Exposure to $32 \mathrm{MIC}$ of cephalexin caused the formation of marked filamentous cells and spheroplast-like structure. $(\times 6,400)$

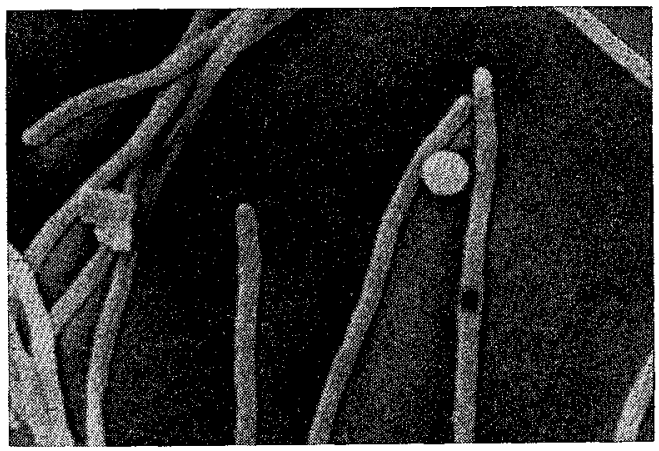

Fig. 3. Exposure to 32 MIC resulted in spherical cell having multiple small saccular outpouchings, presumably spheroplast. $(\times 6,400$ and $\times 4,800$, respectively)

(a)

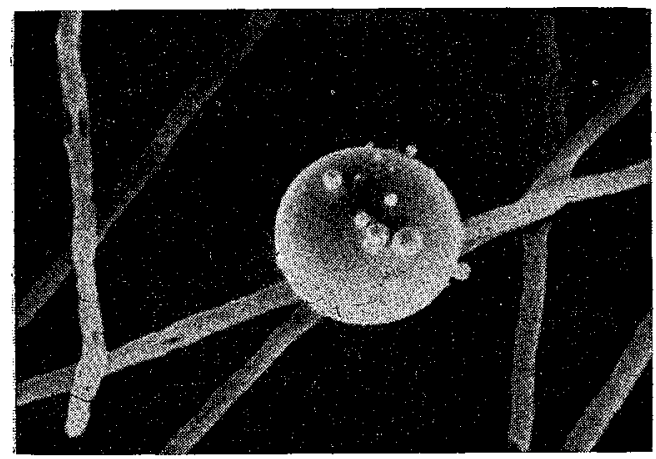

(b)

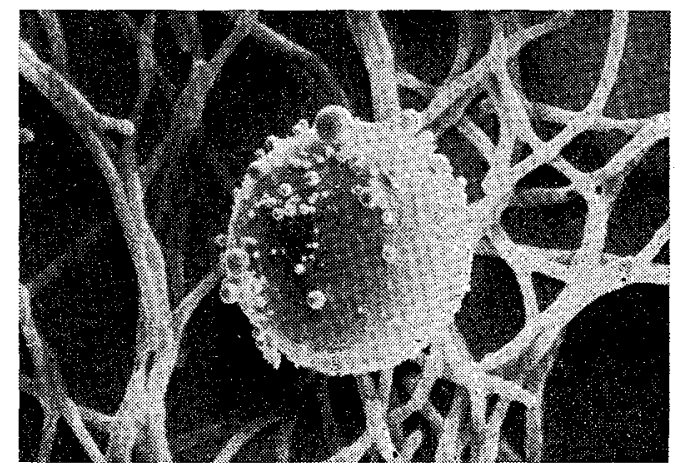

Fig. 4. The lysis of spheroplast-like structure was observed after treatment with $32 \mathrm{MIC}$. ( $\times 4,800$ and $\times 9,600$, respectively)

(a)

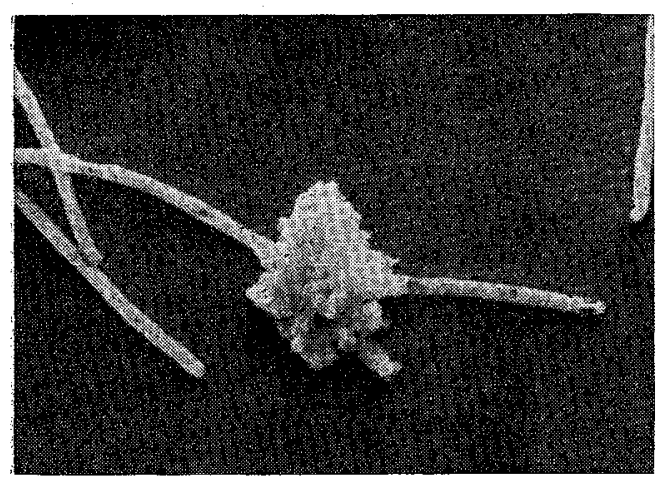

5) Nishrino, T. \& S. NAKazawa : Morphological changes in Staphylococcus aureus and Escherichia coli exposed to cephalexin. Japan. J. Microbiol. 16: 83 94, 1972

6) Kellenberger, E., A. Ryter \& J. Sechaud: Electron microscope study of DNA-contain- (b)

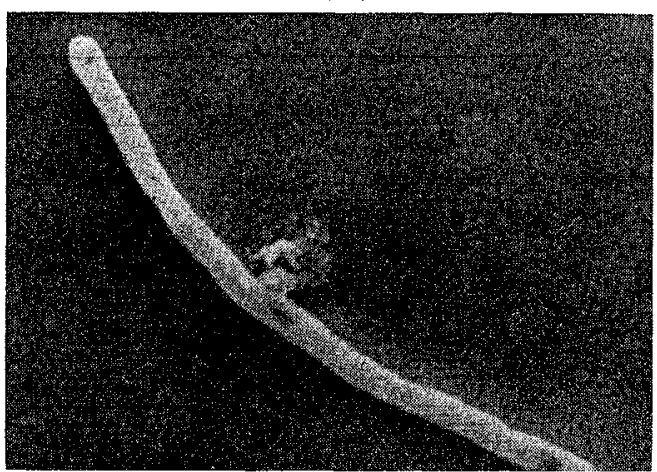

ing plasms. II. Vegetative and mature phage DNA as compared with normal bacterial nucleotide in different physiological states. J. Biophys. Biochem. Cytol. $4: 671 \sim$ 678,1958 